\title{
On the Translation of Foucault's Disciplinary Theory from the Perspective of Marxist Humanity Studies
}

\author{
Yan LV ${ }^{1, *}$ \\ ${ }^{1}$ Northwestern Polytechnical University, College of Humanities and Law, \\ Shaanxi Xi' an 710129, China
}

Keywords: Marxism, Humanity studies, Discipline.

\begin{abstract}
Foucault carries out investigation on the discipline structure from three aspects, namely, body control, power intervention and manufacturing knowledge, he believes that discipline has alienated to a kind of self-interested micro power, imposed all-around constraint and control on humans, deprived humans of freedom and become a kind of irrational subjective. And Marxist Humanity Studies starts from the essential characteristics of "the sum of human's social relations" and demonstrates that discipline is the specific way for humans to adapt to social life and realize allround development. Therefore, Marxist Humanity Studies with "social man" assumption and "people-oriented" as the value core is of important significance in clarifying the rationality of the discipline itself.
\end{abstract}

\section{Dividing Line between the Starting Point and Core Value of Disciplinary Theory}

In the context of Foucault, "discipline" "refers to a kind of special power technology that emerges in the modern times." "It is not only the technology of power intervention, training and monitoring the body, but the means of manufacturing knowledge. Foucault believes that standardization is the core feature of this kind of technology [1]."(Foucault375) - the view of Foucault type understanding based on abstract human nature theory, discipline technology is completely contrary to the value root of the western humanism, namely, "man is the end itself". In discipline, there seems to be no freedom, equality, democracy and other basic values. " 'Individualism' and 'individual freedom' have been promoted to be one of the deeprooted core values of western culture... In the west, 'man is the end itself' refers to that relative to all the other things, the individual itself is the most fundamental and is the existence higher than society and nation"[2]. (Shu-guang Chen 172-173)But in fact, starting from individualism, the whole western traditional human studies "seemingly praise human being and respect human being, but in fact, demean, reject and dismiss human being. Traditional human studies abstract human being 's perceptual, experience factor and make human become non-human - the abstracted human, namely living persons' speculation rationality that is divorced from real life[2]."(Shu-guang Chen 77)Although Foucault has conducted nuanced historical investigation to discipline, he is finally biased towards speculative philosophy in the link of value judgment, denies the objectivity and rationality of discipline in the reality, tried to find universal, eternal, ultimate human nature, and created another "Spiritual Utopia" to settle down based on social reality.

And in the view of Marxist Humanity Studies, distinguishing from the "atomiclike" "individual human being" in the traditional western human studies, the human being in the "people-oriented" should be "social human being ". "Human nature is not a single person's inherent abstract objects, in terms of its reality, it is the sum of all social relations"[3], (Central Compilation \& Translation Bureau 60)and therefore, the individual can understand the rationality of disciplinary technique only when he or 
she stays in the specific realistic social life. Marx once had incisive remarks when criticizing Proudhon:

"Mr. Proudhon's investigation from the perspective of society has ignored and abstracted away those differences that precisely represent certain social relations or formal prescriptions of economy. It's just like someone has said: from the point of view of society, there do not exist slaves and citizens; both of them are human. In fact, it is just the opposite, they are human outside the society. Whether a slave or a citizen is a certain way of social existence of A person and B person. A person himself is not a slave, he becomes a slave through the society in the society where he belongs. To become a slave and a citizen is the regulation of the society, and the relationship between the two people A and B. Here Mr. Proudhon's remarks in terms of capital and products mean that from the point of view of society, there exists no difference between capitalists and workers; actually there exists the difference just only from the point of view of society[4]. "(Central Compilation \& Translation Bureau 176)

The original discipline is the objective law that people find, grasp and use in the labor practice based on their own needs. The disciplinary technique itself is reasonable, normative can be found no matter whether in the training and monitoring body, power intervention or in the perceptual practical activities of manufacturing knowledge, and this kind of normative is reflected as "people-oriented". Then, in the translation of Marxist Humanity Studies, how disciplinary technique reflects the rationality of "people-oriented" in the specific practice of training and monitoring body(body control), power intervention and manufacturing knowledge?

\section{Becoming "social human being": the Rationality of Body Control}

In the view of Foucault, body control and the evolution of punishment technique are closely related. "Human body is controlled in a compulsory, privative, obligatory and restricted system.... Punishment turns from a kind of technology that makes intolerable feelings into a kind of economic mechanism that temporarily deprives of rights"[1] . (Foucault 11) He admits that the direct cause of punishment is committing a crime, "judgment is also aiming at the consequences of human's sexual passion, instinct, abnormal condition, disease, out of control, environment or heredity"[1](Foucault 18), starting from this, Foucault launches a set of detailed technical analysis concerning how to more elaborately tame "man is evil in nature", he will make a painstaking investigation of disciplinary technique until "the purpose of these measures is not to punish illegal behaviors but supervise the person, eliminate his dangerous mindset or transform his criminal tendency, and continue to maintain these measures even after the criminal changes"[1].(Foucault 19)But in the process of "persuading the evil", Foucault completely abandons the original intention of punishing "turning towards good", destructs discipline as a kind of instrumental rationality that is not mixed up with emotions and is controlled throughout the process. Actually, Foucault is not blind to that punishment is the unity of persuading the evil and turning towards good: "we should reveal that punitive measures are not only the 'negative' mechanism of carrying out crackdown, prevention, exclusion and destruction, they also have a series of positive and beneficial effect, a nd their mission is to provide and maintain the effect"[1]. (Foucault 26) "Self-conceit of the speculative rationality often changes into ruthless exaggeration, the expansion of instrumental rationality often changes individuals into the machine and even the components on the machine that can be removed and controlled, and the laws and decrees of value rationality make personal life unable to load so heavy lofty"[5], 
(Zhi-wei Zhang 697) and this makes Foucault have "individuals" isolated out of society, no longer believe that "human being are basically good" and that human being can be independently "at their best", on the other hand, through the deep infiltration of disciplinary technique, the stability of the society no longer needs people's efforts of "turning towards good".

But in the view of Marxist Humanity Studies, first of all, humans are not isolated individuals, "the more we trace back the history, individuals, thus the individuals that are engaged in the production, will be more dependent, belonging to a larger whole"[6],(Central Compilation \& Translation Bureau 21)simply, private ownership leads to the emergence of the ruling class, hence the propertied people have more power, "people will become more selfish, more have no sociality, more alienated with their own inherent essence."[7](Marx 175) Second, it is impractical to simply give a definition on the goodness and evil of human nature from the perspective of synchronicity, human nature is a generation ontology history rather than a entity ontology history. "Therefore, what they are like is in agreement with their production - both consistent with their production, and how they produce. Therefore, what the individuals are like depends on the material conditions for their production[3]."(Central Compilation \& Translation Bureau 68)the only thing we can be sure of is that human being cannot put aside the social community to generally talk about individual freedom, development and liberation, because there do not exist abstract individuals that dissociate outside of the society; individuals are real only in social relations and are exposed to practice[2]. (Shu-guang Chen 121)From the view of diachronic, in the primitive society, for example, individuals must attach themselves to the collective to survive, which make individual interest and public interest united. So primitive people naturally form integrity, honesty, fortitude, bravery, equality and democratic consultations and unconditionally fulfilling public obligations as well as other characters[8]. (Shu-guang Huang 288) Thus it can be seen that for the primitive people, discipline is to comply with the relevant public rules, it is a kind of conscious and autonomous behavior, a kind of necessary activity to maintain the existence of the community. Although with the emergence of private property, human beings have entered the stage of class society, no one can deny: only consciously abiding by the public law can ensure the normal operation of the society; whoever has violated the public interest will be subject to punishment and will be tamed as a "social man" through the deprivation of body control. Therefore, the inherent rationality of body control cannot be found through the technical level narration of Foucault under the abstract human nature, "each person is both the means and the purpose, and one can achieve their own purposes only by becoming the means of others, and can become the means of others by achieving their own purposes... But this kind of common interest is not the reason, it can be said that it only exists behind the individual interests of their own reflection. - General interests or common interests are the comprehensiveness of selfish interests"[9]. (Central Compilation \& Translation Bureau 357-358) Altruistic value orientation and characteristics of common interests of body control can be found on the basis of specific, realistic "social people".

\section{Truly "people-oriented": the Rationality of Power Intervention}

Foucault holds the view that, the constant deepening of body control is due to the needs of continuously strengthening political power. "Power relationship directly controls it, intervenes it, marks it, trains it, tortures it, forces it to complete certain 
tasks, perform certain rituals and emit some signals"[1]. (Foucault 27)From Foucault's sharp and direct words above, we can see that he has painted the discipline formed by power intervention into a book of power technology, "namely the utilitarian rationalization of the details in the aspects of moral obligations and political control"[1]. (Foucault 158). The dismissive emotional outburst of Foucault towards this kind of false rationalization is directly related to the fact that he has got a clear understanding of nature of the capitalist society. "People are subordinate to the rule of 'objects', capital logic dominates everything, the relationship between individual and class, individual and society, man and man becomes hostile, man cannot live with dignity like man, people-oriented space suffers complete exclusion of 'objectoriented' and 'capital-oriented' "[2]. (Shu-guang Chen 191) - This is where the limitation of the capitalist society itself lies, in such a society where the minority rule the majority, although political power is not regarded as a kind of absolute power of personal possession like what is like in the feudal society, its dominating effect still "attributes to scheduling, plot, strategy, technology, operation; ...... still stays in the relational network of tension states and activities [1]."(Foucault 28)With politics as the plot of rulers, power evolves into the power tactics of rulers, in Foucault's view, the relationship between the state and the individual still inherits the tradition of Hobbesian, and will naturally lead the discipline under the power intervention to present a form of alienation. This also means that in the capitalist society, "joint activity itself is not voluntarily but naturally formed, so in the view of these individuals, this kind of social power is not their own joint strength, but some alien, compulsory force beyond them. They have little knowledge of the origin and development trend concerning this kind of force; so they can no longer drive this kind of force, on the contrary, this kind of force is now experiencing a series of unique development stages that not only do not depend on people's will and actions but dominate people's will and actions instead[3]. (Central Compilation \& Translation Bureau 538)The implication is that whether power intervention is rational has a very close relationship with social form, when the discipline under power intervention becomes a kind of voluntary joint activity, this kind of joint power will not be alien. Therefore, in the view of Marxist Humanity Studies, the rationality of power intervention may be only presented in the socialism and communism society that is really "people-oriented". Because "there, each person's free development is the condition of all human being's free development[3]."(Central Compilation \& Translation Bureau 294)

Foucault is unable to realize the rationality of power intervention, in addition to being limited by the capitalist society's own limitations objectively, subjectively he also ignores the dialectical unity between the disciplining person and the disciplined person. In the discussion of "public execution", Foucault actually mentioned such a kind of discipline situation of power intervention, that is, "people were attracted to watch the scenes which are designed to intimidate them" [1] (Foucault 65), and admits that in the disciplinary process of the rulers to the people, objectively he is also faced with the rejection of the audience to punishment power:

When suffering the public execution, criminals will be subject to the most severe punishment, so they are allowed to have a moment of arbitrary behaviors. With the umbrella of "will be put to death", criminals can speak arbitrarily, and the crowd of onlookers will give applause...This kind of execution ceremony originally should only show the deterrent force of the monarch, but there is the side of a carnival: the law will be overthrown, the authority will be teased, the criminal will become a hero, and the honor and disgrace will be reversed...When people view the judgment 
unjust...Especially there will be the above situations [1]. (Foucault 66)

This statement, in fact, has shown that the intervention of power will be subject to the rejection of the disciplined person, but Foucault merely mentions lightly and describes this kind of unjust, unequal and resistance to involuntary discipline as "social unrest" - Foucault is not always against the bondage and control of discipline power on human being, isn't he? Why is he not willing to positively affirm the subjective initiative of the human being? - Actually this precisely reflects that Foucault himself who starts from individualism will see human as atomic-like monatomic individuals. He only sees the nature of human's realistic social relations, and that man is the sum of all social relations, but cannot see human's labor es sence and practice essence, so he will have a direct and isolated understanding of human nature, can only see that human is restricted by social relations, which will lead to fatalism, as if human is the passive product of social relations, social environment and living conditions [10]. In short, the reason why Foucault criticizes that discipline power is a kind of "docile-utilitarian" technology is that he first views people as the "objects" without initiative. Therefore, he firmly believes that "public execution is not to reconstruct justice but to revive power"[1]. (Foucault 53)Maintaining the stability of power intervention can only change the punishment and repression of illegal activities into a regular function, synchronically developing with the society; not to punish less, but to punish more effective; perhaps it is suitable to reduce the severity of punishment, but the purpose is to make the punishment more universal and necessary; make punishment power embedded in the society itself"[1]. (Foucault 91)

Then how the rationality of power intervention is embodied in the dialectical relationship between the disciplining person and the disciplined person? In the view of Marxist Humanity Studies, the question in the first place does not depend on "the public power with continuous effect" [1] (Foucault 90), but lies in whether the system design, system arrangement and system operation carried out under this kind of public power can proceed from public interest and really achieve "people-oriented", namely "system exists for people rather than people exist for system. People are the end, system must confirm the value of people, respect the dignity of people, meet and develop justified and reasonable personal interest, protect and promote the people's survival rights, development rights, freedom rights, equality rights and property rights"[2]. (Shu-guang Chen 190)What people reject is the discipline that is unable to enrich and perfect themselves, and the discipline that cannot proceed from realistic and social people. At the same time, only through people's rejection, it can be found that there have already existed the defects of discipline system so as to carry out adjustment and improvement in the level of power intervention and ensure the continuous publicity of public power. Finally through the two-way interaction between the disciplining person and the disciplined person, better reflect the rationality of power interference.

\section{Originating from "perceptual practical activities": the Rationality of Manufacturing Knowledge}

When body control forms functions under power intervention, the whole set of technology forms on the knowledge concerning the body. But this knowledge is added with a quotation mark in Foucault's writing:

"This kind of technology is divergent, and almost does no form coherent and systematic discourse; it is often a variety of sporadic fragments; it uses a set of all sorts of tools and methods. Although the results are uniform, but in general, it is only 
a kind of operation of various forms. In addition, it is not fixed in a particular kind of system institution or state machine. They all turn to it, use, select or implement some of his methods. However, in terms of its mechanism and effect, it is in another dimension [1]."(Foucault 28)

"Divergent", "not forming coherent", "sporadic", "fragments", "of various forms", "not fixed"... It can be felt from these attributive modifier used by Foucault, he himself will see the knowledge made from discipline as fragmented, faulted, accidental, unstable, so he is seriously suspicious of whether such "knowledge" possess rationality, only relative to its mechanism and the effect, there exists an effective field, in this sense, Foucault calls discipline knowledge as the "micro physics of power" used by the state machine[1] (Foucault 28), "although there is a certain kind of continuity (they are connected into this kind of continuous form through a series of complex mechanisms), however, there is neither similarity nor homology but only the particularity of mechanism and modal"[1].(Foucault 29)As stated earlier, this kind of cold power operation technology and power practice that "cannot see people" is because he, who is in a capitalist society that is "object-oriented", "power-oriented" rather than "people-oriented", has already potentially returned people to homogeneous atomic-like individuals as his theoretical presupposition.

Therefore, after people's subjective initiative is ignored, Foucault fully explores "micro physics principle" of discipline knowledge, the more detailed this kind of exploration will be, the more ivory-towered deconstructions are made on discipline so that it is unable to summarize its macro regularity, such fragmented knowledge will be more special and accidental, more unrepeatable and invalidated, in the end, it will certainly lose the objectivity of discipline knowledge, showing value loss, lack of explanatory power and a series of irrationality.-What's worth pondering is that, Foucault's book Discipline and Punishment concerning the "history of present" exactly hopes to finally become the true knowledge that can withstand test, is futureoriented and can guide people to obtain freedom through the historical inspection of discipline.

In addition, Foucault also sets up the ontological status of "power - knowledge", and firmly believes that the cognitive subject, object, modal cannot escape the "slavery" of "power - knowledge" system:

"Power creates knowledge (besides, not only because knowledge serves for power, power encourages knowledge, not only because knowledge is useful, power uses knowledge); power and knowledge are directly related to each other... Cognitive subject, cognitive object and cognitive modal should be regarded as the numerous effects of power - knowledge as well as other basic joint relations and their historical changes. In short, it is not the activities of cognitive subject that produce a certain knowledge system which is helpful for the power or resistance to the power, on the contrary, 'power - knowledge' penetrates the development and change as well as contradictions and struggles of 'power - knowledge' and constituting 'power knowledge', and determines the form of knowledge and its potential fields."'[1] (Foucault 29-30)

Foucault acknowledges that power has created knowledge, but this kind of knowledge is created by such a kind of power - possesses material strength, the sum of the realistic social relations of the people with fatalistic colors - rather than formed by the labor practices of the cognitive subject. In other words, Foucault heaves a sigh in front of the "unreasonable" disciplinary power he himself assumes, he changes the 'power - knowledge' system of discipline into a transcendent entity -similar to Hegel's "absolute spirit", transform, change and develop through the 
contradictions of 'power - knowledge' system itself, determines the depth and breadth of cognitive subject practical activities, namely, to what extent it is able to acquire knowledge and in which fields it is able to recognize knowledge. it may well be asked, how can Foucault's substantial ontology human studies reasoning line, namely, "regarding the concept as the subject anywhere, and changing the subject of the reality in the proper sense ......into predicate"[11](Central Compilation \& Translation Bureau 14) can push aside the bravado of 'power - knowledge' system, and find the differences between discipline and alienated discipline?

In the view of Marxist Humanity Studies, therefore, the ontology that offends and forgets "people" and the theory of knowledge that cancels people's subjective initiative will only get an "abstract person" or an "instrumental person", then the discipline knowledge based on this will be sure to pull out people's richness and integrity and show "striking impoverishment", so it is unable to see the rationality of discipline knowledge. We have previously demonstrated that, only by starting from realistic, concrete "social people", following and utilizing objective laws, it is able to ensure that people obtain freedom in the community; only by taking advantage of public power design and implementing discipline system under the guidance of "people-oriented", it is able to make people voluntarily safeguard public interests. While Archimedes' Point of Marxist Humanity Studies — "social man" assumption and "people-oriented" core are not abstract and speculative. "The premise we start to talk about is not arbitrary... These are some individuals in reality, and their activities and their material living conditions... These premises can be confirmed by pure empirical methods"[3], (Central Compilation \& Translation Bureau 66-67)and therefore, the rationality of body control and power intervention is derived from human beings' extensive and profound discipline practical activities over thousands of years, "people's perceptual activities... This kind of activity, this kind of continuous emotional labor and creation and this kind of production are precisely the foundation of the entire existing perceptual world"[3].(Central Compilation \& Translation Bureau 77)This also means that Marxist Humanity Studies return the perceptual knowledge of discipline activities from the "other world" to the "this world", thus the reconstructed whole set of objective, historical discipline knowledge will be bound to enable us to have a more profound understanding of human society and humanity itself. Such knowledge is summed up from human's perceptual practical activities, and can more correctly guide human's perceptual practical activities. "In the place where speculation terminates and in the face of real life, it is the place for the beginning of the real empirical science, which describes people's practical activities and actual development process. The empty words concerning consciousness will be terminated, and they will be sure to be replaced by true knowled ge [3]."(Central Compilation \& Translation Bureau 73-74)Marxist Humanity Studies do not mean to create the true knowledge of manufacturing discipline, but be able to recognize the rationality of discipline, and clarify that it is beneficial for people's all-round development, beneficial for the harmonious coexistence between man and nature and beneficial for the substantive characteristics of community solidarity.

\section{Ackno wledge ment}

This research was financially supported by the western projects of National Social Science Foundation, and is the phase achievement of (15XKS011) established project. 


\section{References}

[1] M. Foucault, Translated by Bei-cheng Liu, Yuan-ying Yang. Discipline and Punishment: The Birth of Prison. SDX Joint Publishing Company, Beijing, 2012.

[2] Shu-guang Chen. To Face Perceptual-Life Itself: On The Ontological Revolution Of Marx's Hominolog. Beijing Normal University Press, Beijing, 2012.

[3] Central Compilation \& Translation Bureau. Selections of K. Marx and F. Engels, Vol. 1.People's Publishing House, Beijing.1995.

[4] Central Compilation \& Translation Bureau. The Complete Works of Max and Angles, Vol. 32.People's Publishing House, Beijing. 1998.

[5] Zhi-wei Zhang. History of Western Philosophy. China Renmin University Press, Beijing. 2002.

[6] Central Compilation \& Translation Bureau. The Complete Works of Max and Angles, Vol. 46 (Book One).People's Publishing House, Beijing.1979.

[7] Marx. The Manuscript of Economics and Philosophy in 1844.People's Publishing House, Beijing. 2000.

[8] Shu-guang Huang. Marxist Liberation Theory and Marxist Conception of History. Jiangxi People's Publishing House, Jiangxi. 2011.

[9] Central Compilation \& Translation Bureau. The Complete Works of Max and Angles, Vol. 31.People's Publishing House, Beijing.1998.

[10] Li-qing Nie, Yong-ting Zheng. Modern Philosophy, 2(2007) 104-109. In Chinese.

[11] Central Compilation \& Translation Bureau. The Complete Works of Max and Angles, Vol. 3 .People's Publishing House, Beijing. 2002. 